\title{
"A general model for treatment of protests and no-answer responses in contingent valuation method"
}

\begin{tabular}{|c|c|}
\hline & Pei-Ing Wu (D) https://orcid.org/0000-0002-5097-2727 \\
\hline AUTHORS & $\begin{array}{l}\text { Szu-Hao Chen } \\
\text { Je-Liang Liou }\end{array}$ \\
\hline ARTICLE INFO & $\begin{array}{l}\text { Pei-Ing Wu, Szu-Hao Chen and Je-Liang Liou (2017). A general model for } \\
\text { treatment of protests and no-answer responses in contingent valuation method. } \\
\text { Environmental Economics, 8(2), 38-49. doi:10.21511/ee.08(2).2017.04 }\end{array}$ \\
\hline DOI & http://dx.doi.org/10.21511/ee.08(2).2017.04 \\
\hline RELEASED ON & Friday, 09 June 2017 \\
\hline RECEIVED ON & Friday, 12 May 2017 \\
\hline ACCEPTED ON & Friday, 26 May 2017 \\
\hline LICENSE & $\begin{array}{l}(c) \text { EY-No } \\
\text { This work is licensed under a Creative Commons Attribution-NonCommercial } 4.0 \\
\text { International License }\end{array}$ \\
\hline JOURNAL & "Environmental Economics" \\
\hline ISSN PRINT & $1998-6041$ \\
\hline ISSN ONLINE & $1998-605 X$ \\
\hline PUBLISHER & LLC "Consulting Publishing Company "Business Perspectives" \\
\hline FOUNDER & LLC "Consulting Publishing Company "Business Perspectives" \\
\hline
\end{tabular}

NUMBER OF REFERENCES

42
NUMBER OF FIGURES

1
NUMBER OF TABLES

4

(C) The author(s) 2023. This publication is an open access article. 
Pei-Ing Wu (Taiwan), Szu-Hao Chen (Taiwan), Je-Liang Liou (Taiwan)

\title{
A general model for treatment of protests and no-answer responses in contingent valuation method
}

\begin{abstract}
This study formulates a general model to account for the protest responses and no-answer replies in contingent valuation method (CVM) and should be interesting to the readers in Environmental Economics both from the methodological aspect in CVM and from the application aspect in benefit evaluation of all kinds of environmental issues and natural resources conservation. This general model is applicable to all kinds of elicitation methods in CVM. The merits of this general model are simplicity in estimation and simultaneously accounting both for protest and noanswer responses. This general model certainly can offer future CVM applications a good direction and guidance in resolving these troublesome issues in this extensive use valuation method. Creation of inverse Mills ratio is the distinctive step in this general model. The results generally indicate that these ratios are significantly different from zero. This means that accounting for these Mills ratios does have an important role in such modification when protest responses and/or no-answer responses are both taken into account. The results show that overall total WTPs from the general model with inclusion of protest and no-answer responses under different types of elicitation formats are higher than those estimated by traditional treatment. The degree of underestimation of traditional treatment is between $26 \%$ and $67 \%$. That is, the general model proposed here for treating protest and/or no-answer responses in CVM can account for the full information which might be potentially omitted or inappropriately dealt with in the estimation.
\end{abstract}

Keywords: contingent valuation method, direct WTP revelation, hybrid type, inverse Mills ratio, pure discrete choice.

JEL Classification: C51, C80, Q51.

Received on: $12^{\text {th }}$ of May, 2017.

Accepted on: $26^{\text {th }}$ of May, 2017.

\section{Introduction}

Contingent valuation method (CVM) is a widely used method for evaluation of non-market goods and services. All elicitation methods in the design of CVM can be classified into three groups. One is the direct revelation of willingness to pay (WTP), such as open-ended payment card, and bidding game, another is the pure discrete choice type, such as single-bounded, double-bounded, and even triplebounded, and the other is the hybrid type format with a combination of discrete choice and open revelation, such as single-bounded with open question follow-up and double-bounded with open question follow-up (Alvarez-Farizo, 1999; Barrio and Loureiro, 2010; Bateman et al., 1995; Bishop and Heberlein, 1979; Langford et al., 1996; Randall et al., 1974; Scarpa and Bateman, 2000; Strazzera et al., 2003).

For either type of elicitation method, protest responses inevitably occur for various reasons

(c) Pei-Ing Wu, Szu-Hao Chen, Je-Liang Liou, 2017.

Pei-Ing Wu, Professor and Chair, Ph. D., Department of Agricultural Economics, National Taiwan University, Taiwan.

Szu-Hao Chen, Assistant Research Fellow, M.S., Research Division IV, Taiwan Institute of Economic Research, Taiwan.

Je-Liang Liou, Associate Research Fellow, Ph.D., The Center for Green Economy, Chung-Hua Institution for Economic Research, Taiwan.

This is an Open Access article, distributed under the terms of the Creative Commons Attribution-NonCommercial 4.0 International license, which permits re-use, distribution, and reproduction, provided the materials aren't used for commercial purposes and the original work is properly cited.
(Lindsey, 1994; Jones et al., 2008; Meyerhoff and Liebe, 2009; Meyerhoff et al., 2012). The protest responses might be identified as zero responses or could also be revealed as "no" or "no-no" replies depending upon the elicitation format. Payment vehicle, policy intervention, institutional setting, lack of comprehension of the task, insufficient information, ethical objections, or motivation to free-ride are possible causes for protest responses, which will cause the problem of sample selection bias (Atkinson et al., 2012). Without proper modification and correction, the aggregate measure of total benefits for the concerned goods and services will be biased either upwards or downwards.

Moreover, a National Oceanic and Atmospheric Administration (NOAA) expert panel (Arrow et al., 1993) suggests not pushing respondents to choose between "yes" or "no". An option of "no-answer"1 should be offered in the discrete choice stage for respondents who cannot clearly make a decision between "yes" and "no" choices. Presser and Schuman (1980) also discover that number of nonresponses tends to increase if no option of "noanswer" was provided. As such, the respondent confronts three options of choices instead of two

\footnotetext{
${ }^{1}$ The option of "no-answer" suggested by NOAA expert panel tends to catch the answers of indifference between "yes" and "no", inability to make a decision without more time and information, preference toward other decision mechanism, and/or uninteresting to the survey. Surveys that design a "no-answer" option in the past studies might call this option as "don't know" and/or "uncertainty" depending upon the reasons that survey tries to emphasize.
} 
options, "yes" and "no", in the elicitation formats related to choice types. Under such circumstances, the decision tree for the analysis should be different from that when only "yes" and "no" options are provided, as in most research conducted in the past. Similarly, there are various kinds of reasons for choosing the option of "no-answer" (Alberini et al., 2003; Balcombe and Fraster, 2009; Li and Mattson, 1995; Ready et al., 2001; Shaikh et al., 2007; Wang, 1997). No matter what reasongives rise to noanswer responses, studies in the past conducted with the help of CVM rarely include "no-answer" for respondents as another option. Consequently, modification and correction for sample with such responses is hardly seen in the literature.

There are some methods to modify and/or correct the sample with protest or no-answer responses in past studies. Among these, the easiest method is to remove these types of responses. It is obvious that sample will, then, be reduced and be further biased. The inference from the estimation results will be invalidated accordingly (Jorgensen et al., 1999). Examples can be found in the studies done by Dziegielewska and Mendelsohn (2007), Halstead et al. (1992), Jones et al. (2008), Meyerhoff and Liebe (2006), and Whitehead et al. (1993). Another method is to incorporate protest responses and estimate the whole valid sample with a censored Tobit model. The underlying theory for doing so is the assumption that all zero responses are treated as a corner solution. Examples can be found in the studies by Alvarez-Farizo (1999), Carson and Sun (2007), and Havet et al. (2012).

Even more complicated and delicate modification and correction is estimation by a double-hurdle model (Cragg, 1971). This, then, requires Heckman's (1979) two-stage procedure to estimate the sample selection type of model. Studies doing so include DalmauMatarrodona (2001) and Strazzera et al. (2003). Accordingly, the full information maximum likelihood method is the most efficient method to deal with the sample selection issue (Strazzera et al., 2003). Research done by Brouwer (2012) and Fonta et al. (2010) also uses the full information maximum likelihood method to modify samples with protest responses.

The drawback of the full information maximum likelihood method is, however, that it is too complicated to estimate. It is normally difficult to obtain convergence in the estimation due to its nonlinearity ${ }^{2}$. If more information is collected from

\footnotetext{
${ }^{2}$ Estimation of nonlinearity involves searching for the local optimization or the global optimization. Selection of good starting points of coefficients may not always fulfill the ideal location or conform to the expectation. Thus, it normally takes longer time in estimation to get convergence if it is not impossible.
}

all the respondents, then, an alternative method, the latent class model, which treats protest responses as an attitudinal factor, is an alternative method (Zoltán, 2011). Meyerhoff and Liebe (2006; 2009) and Cunha-e-Sá et al. (2012) extend the idea of the latent class model to deal with protest responses. Other varieties of models for treating protest responses include one named multiplehurdles by $\mathrm{Wu}$ et al. (2004), and one named the spike model by Reiser and Shechter (1999). These methods are too complicated to achieve estimation convergence. As such, these methods are of limited usefulness in dealing with the protest responses.

As with "no-answer" responses, there are few studies which correct and modify them, because most research does not include an option of "no-answer" in the questionnaire. Even if there is an option of "noanswer" designed into the questionnaire, previous studies just remove these responses before estimation proceeds. This will cause a problem similar to protest responses. That is, the more the "no-answer" responses are removed, the more biases occur. Groothuis and Whitehead (2002), Wang (1997), and Wu et al. (2004) have designed different models to treat "no-answer" responses. Even if the focus of modification is to include responses of "no-answer", there is no general rule for how to treat these responses.

Moreover, previous studies correct or modify protest responses and no-answer responses separately. No general model, however, is appropriately employed to correct or modify protest and no-answer responses simultaneously. Thus, models for modification from previous research not only don't fully account for both protest responses and no-answer responses, but also are not suitable for all kinds of elicitation methods in CVM surveys.

Thus, construction of a general model, which is desirable and empirically applicable, is a new challenge for this field. Design of the model is not only necessary for all kinds of elicitation formats, but also essential to treat protest responses and no-answer responses concurrently. Additionally, estimation of this general model should have characteristics of higher efficiency and easier estimation than the traditional approaches. Thus, the purposes of this study are, firstly, to formulate a general model to account for the protest responses and no-answer replies for all types of elicitation methods. The model is, then, applied to a set of data from a previous study by Hung et al. (2012). Finally, the results estimated from the models constructed in this study are compared with those derived by traditional models. 
The remainder of the paper is organized as follows. Section 1 constructs the general model. Section 2 is the specification of modification models. Section 3 presents the results and analyses, and final section concludes. This study intends not only to suggest a model, which is theoretically and empirically sound, but also to give a comprehensive progress record for all the models that have been developed so far for correcting protest and no-answer responses.

\section{General model for non-protest, protest, and no-answer responses}

The general model, which modifies and corrects sample with protest and/or no-answer responses and accommodates all types of elicitation formats classified in this study, is presented in Fig. 1.

In any type of elicitation method, the first stage is to estimate the probability of each response, and to prepare its related information for WTP estimation.

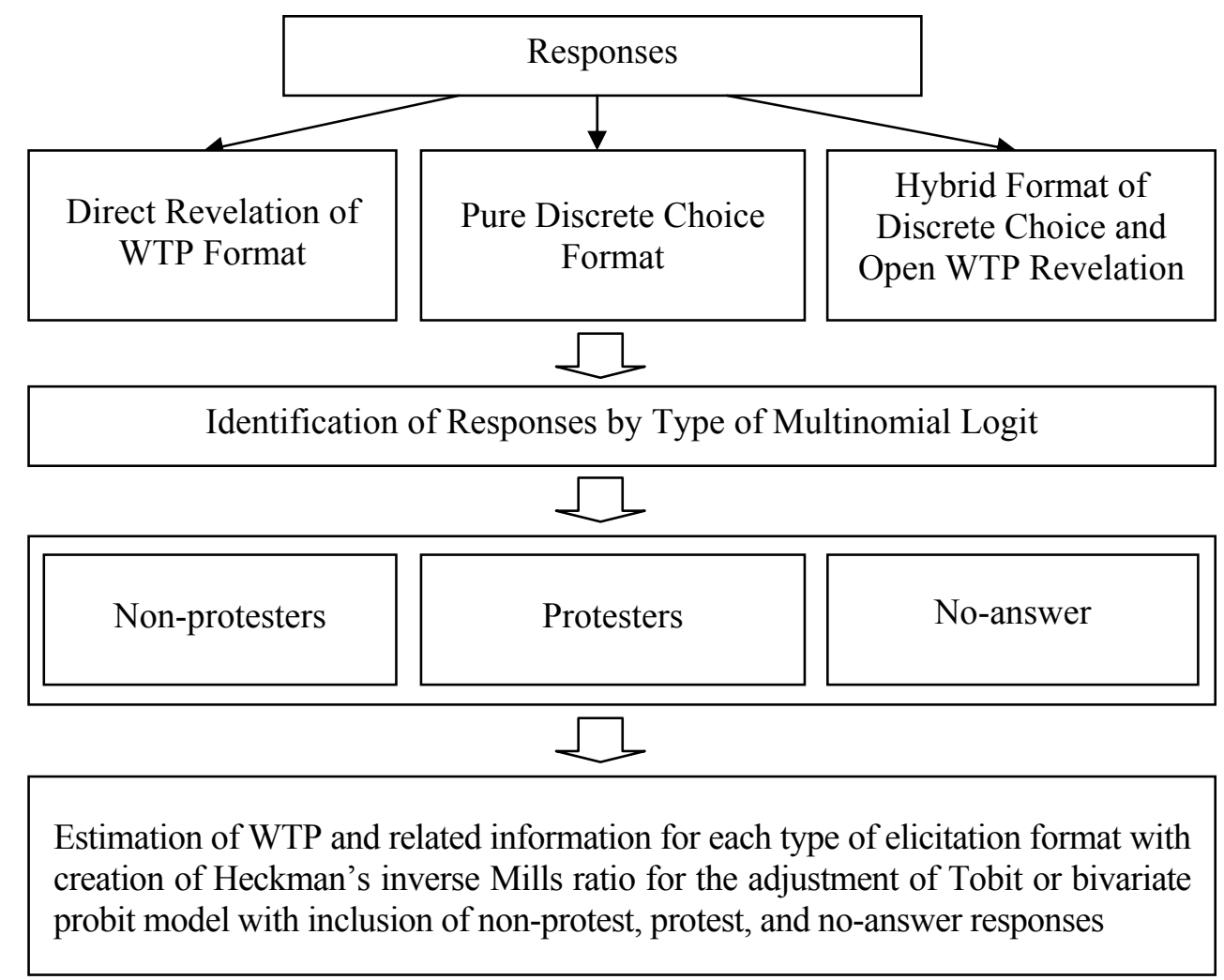

Fig. 1. The general model for non-protest, protest, and no-answer responses

The second stage is, then, to estimate WTP, in which the protest and no-answer responses are all included ${ }^{3}$. Along such a general model, the procedure for estimation of each type of elicitation method is outlined below.
1.1. Probability estimation of each type of response. The multinomial logit stated in equation (1) is employed to estimate the probability of each response:

$$
P_{i j}=\exp \left(\alpha_{m}+\beta_{m} X_{i j}\right) /\left(1+\sum_{j=1}^{3} \alpha_{m}+\beta_{m} X_{i j}\right) \quad i=1,2,3, \ldots, n \quad j=1,2,3,
$$

where $P_{i j}$ is the probability of a designated response, $i$ is the response and $i=1,2,3, \ldots, n$, and $n$ is the total number of responses. Additionally, $j$ is the response type, and we assume $j=1$ is non-protest, $j=2$ is protest, and $j=3$

\footnotetext{
${ }^{3}$ The general model constructed in this study is completely different from the idea proposed by Hsiao and Sun (1998). Their study intends to fill in missing data for certain questions or specific responses in the survey. The protest responses or don't know/uncertainty responses are
}

is no-answer responses. The inverse Mills ratio is transformed from a multinomial logit model. There are various ways to deal with such a problem. Accordingly, Bourguignon et al. (2007) recommended that the DMF developed by Dubin and McFadden (1984) be adopted for the

identified afterwards. The occurrence of potential protest responses or don't know/uncertainty responses can be determined by their corresponding probability beforehand for the model proposed in this study. 
second stage estimation ${ }^{4}$. As such, the inverse Mills ratios are presented as (2)

$$
\begin{aligned}
& \text { MLIMRA }=\ln \left(P_{i 1}\right)+\left(P_{i 2} \times \ln \left(P_{i 2}\right)\right) /\left(1-P_{i 2}\right), \\
& \text { MLIMRF }=\ln \left(P_{i 1}\right)+\left(P_{i 3} \times \ln \left(P_{i 3}\right)\right) /\left(1-P_{i 3}\right),
\end{aligned}
$$

where MLIMRA and MLIMRF are the inverse Mills ratios calculated for non-protest and protest responses.
1.2. Estimation of WTP under each elicitation format. 1.2.1. Direct revelation of WTP format. After estimation of probability of each response and WTP for protest responses and no-answer responses, the estimation of WTP for all responses, including protest, non-protest, and no-answer responses, can be achieved by equation (3):

$$
\begin{aligned}
\text {OPWTP}_{i j}=f\left(\beta_{E} X_{i j}, \gamma_{A E} \operatorname{MLIMRA}_{i 1}, \gamma_{F E} \operatorname{MLIMRF}_{i 1}\right) & +\varepsilon_{E i 1} \\
i & =1,2,3, \ldots, \mathrm{n} \quad j=1,2,3,
\end{aligned}
$$

where $\beta_{E}$ is the coefficient to be estimated, $\gamma_{A E}$ and $\gamma_{F E}$ are coefficients of inverse Mills ratios from the multinomial logit model, which is used to adjust for non-protest and protest responses, respectively, under the multinomial logit model and $\varepsilon_{E 1}$ is the error term.
1.2.2. Pure discrete choice format. Under expenditure difference interpretation, the bivariate probit model is employed to identify the differences among responses. The inverse Mills ratio generated from the multinomial logit model is, then, used as one explanatory variable structured in equation (4):

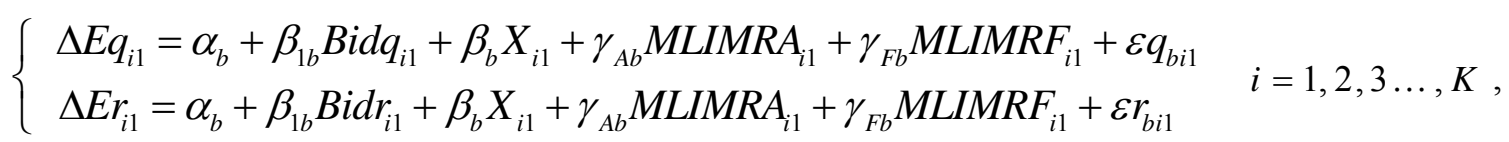

where $\Delta E q_{i 1}$ is the response to the first offered bid price and $\Delta E r_{i 1}$ is the second one. Additionally, $B i d q$ and Bidr are the first and second bid price, respectively. And $\alpha_{b}$ is the constant term and $\beta_{1 b}$ and $\beta_{b}$ are vectors of coefficients to be estimated. $\gamma_{A b}$ and $\gamma_{F b}$ are coefficients for inverse Mills ratios from the multinomial logit model, and $\varepsilon q_{b 1}$ and $\varepsilon r_{b 1}$ are error terms.

The estimation of WTP from the bivariate probit model requires Heckman's inverse Mills ratio to avoid the potential sample selection bias. The Heckman inverse Mills ratio under the bivariate probit model is computed as in equation (5) below (Heckman, 1979):

$$
H I M R=\frac{\varphi\left(\frac{b \alpha-\mu}{\sigma}\right)}{1-\phi\left(\frac{b \alpha-\mu}{\sigma}\right)}
$$

where $\mu$ and $\sigma$ are the mean and variance from the bivariate probit model, and $\alpha$ is a constant term. Additionally, $\varphi$ is the probability density function of the normal distribution for the discrete choice procedure, and $\phi$ is the cumulative density function of the normal distribution in the choice process.

In order to be comparable with the results estimated from the other two categories of elicitation methods, the Tobit model is conducted for the WTP estimated from the previous stage under such condition as in equation (6):

$$
D W T P_{i 1}=f\left(\beta_{1 D} X_{i 1}, \omega_{D} H I M R_{i 1}\right)+\varepsilon_{D i 1} \quad i=1,2,3, \ldots, K,
$$

where $\beta_{1 D}$ is the vector of coefficients to be estimated, $\omega_{D}$ is the coefficient for Heckman's inverse Mills ratio $\left(H I M R_{1}\right)$, and $\varepsilon_{D i 1}$ is an error term.

\footnotetext{
${ }^{4}$ There are various methods to estimate probability for each category of response. In order for such results to be appropriately used in further analyses to avoid potential bias, correlation between different levels of decisions has to be taken into account. The method developed by Dubin and McFadden (1984) is one such method which not only has such characteristics, but also is suitable for the data at hand.
}

1.2.3. Hybrid type format with discrete choice and open WTP revelation. In order to account for protest responses and no-answer response for its estimation of WTP, the Heckman inverse Mills ratio (HIMR) through discrete choice for non-protest WTP estimation is included in the following Tobit model. Furthermore, it is to predict WTP for no-answer responses by using the non-protest WTP estimation. Together with all other WTP estimations, the full sample with predicted WTPs for no-answer responses and predicted WTPs for protest responses is estimated by the following equation (7): 


$$
\text { TWTP }_{i j}=f\left(\beta_{T} X_{z}, \omega_{T} H \text { IMR }_{i 1}\right)+\varepsilon_{T i 1} \quad i=1,2,3, \ldots, \mathrm{n} \quad j=1,2,3,
$$

where $\beta_{T}$ is the vector of coefficients to be estimated, $\omega_{T}$ is the coefficient for Heckman's inverse Mills ratio, and $\varepsilon_{T 1}$ is an error term.

\subsection{Traditional treatment of protest and/or no-} answer responses. To compare the results estimated from the general model developed in this study, which includes protest and no-answer responses, with those from traditional treatments of protests, estimations for the direct revelation of WTP format and for the hybrid type format with discrete choice and open WTP revelation are similar to equation (3) and (7) without variables of $M L I M R A_{1}, M L I M R F_{1}$, and $H I M R_{1}$. Equation (6) without variable of $H I M R_{1}$ is used to estimate the pure discrete choice format under traditional treatment of protests. Since there is no traditional design to modify both protest and no-answer responses, as this study does, the comparison is limited to the inclusion of protest responses only.

\section{Specification of estimation models}

2.1. Data source. In order to examine the applicability of the general model constructed here and demonstrate its simplicity in estimation, a set of data accomplished by Hung et al. (2012) is employed. The data are a benefit evaluation of the Changhua Coastal Wetland with a total sample of 405 respondents. Without conducting too many and complicated surveys, these data are collected by double-bounded with open-ended follow-up CVM elicitation method perfect for empirically examining inclusion of protest and/or no-answer responses for all types of elicitation methods proposed in this study. This Wetland with total area of 7,300 acres and with coastline of about 13 kilometers comprises four parts and is the largest wetland in Taiwan. Furthermore, this Wetland is a unique mud-flat in Taiwan with various biological conservation resources, such as birds, plants, and the endangered Sousa chinensis, also known as the Indo-Pacific hump-backed dolphin. All of these are scarce natural resources requiring protection through good management of this Wetland.

\subsection{Variables selection and model specification} for probability estimation. The general model first identifies the types of responses in the data. The probability of each response belonging to protest, non-protest, or no-answer response is predicted by equation (8). The explanatory variables include whether the respondent has visited the Wetland (Visit), years of education (Eduyear), annual household income (Income), membership of an environmental organization (Organiz), volunteer in anenvironmental organization (Volunteer), and whether the respondent has donated to an environmental organization (Donate). That is, equation (8) is the empirical specification for equation (1):

$$
\begin{gathered}
P_{i j}=\exp \left[\left(\alpha_{m}+\beta_{1 m} \text { Visit }_{i j}+\beta_{2 m} \text { Eduyear }_{i j}+\beta_{3 m} \text { Income }_{i j}+\beta_{4 m} \text { Organiz }_{i j}+\beta_{5 m} \text { Volunteer }_{i j}+\beta_{6 m} \text { Donate }_{i j}\right) /\right. \\
\left.\left(1+\sum_{j=1}^{3}\left(\alpha_{m}+\beta_{1 m} \text { Visit }_{i j}+\beta_{2 m} \text { Eduyear }_{i j}+\beta_{3 m} \text { Income }_{i j}+\beta_{4 m} \text { Organiz }_{i j}+\beta_{5 m} \text { Volunteer }_{i j}+\beta_{6 m} \text { Donate }_{i j}\right)\right)\right] \\
i=1,2,3, \ldots, \mathrm{n} \quad j=1,2,3
\end{gathered}
$$

where $P_{i j}$ is the probability of a typical response belonging to a certain format of response, $i$ represents response, $i=1,2,3, \ldots, n, n$ is the number of total responses for a certain type of response, $j$ represents format of response, $j=1$ is a non-protest response, $j=2$ is a protest response, and $j=3$ is a response of noanswer. Finally, $\alpha_{m}$ is a constant term and all $\beta_{m}$ s are coefficients to be estimated.

\subsection{Variable selection and model specification} for different WTP revelation formats. 2.3.1. Format of direct revelation of WTP. For the direct revelation of WTP elicitation format, an empirical specification for equation (3) is required. The estimation of WTP with inclusion of protest responses modified by an inverse Mills ratio, which is estimated by a multinomial logit model, is shown in the equation (9):

$$
\begin{aligned}
& \text { OPWTP }_{i j}= \alpha_{E}+\beta_{1 E} \text { Visit }_{i j}+\beta_{2 E} \text { Environ }_{i j}+\beta_{3 E} \text { Age }_{i j}+\beta_{4 E} \text { Eduyear }_{i j}+\beta_{5 E} \text { Occ }_{i j}+\beta_{6 E} \text { Occ }_{i j} \\
&+\beta_{7 E} \text { Occ }_{i j}+\beta_{8 E} \text { Occ }_{i j}+\beta_{9 E} \text { Income }_{i j}+\beta_{10 E} \text { Organiz }_{i j}+\beta_{11 E} \text { Volunteer }_{i j} \\
&+ \beta_{12 E} \text { Donate }_{i j}+\beta_{13 E} \text { Distance }_{i j}+\gamma_{A E} \text { MLIMRA }_{i 1}+\gamma_{F E} \text { MLIMRF }_{i 1}+\varepsilon_{E i 1} \\
& i=1,2,3, \ldots, \mathrm{n} \quad j=1,2,3
\end{aligned}
$$


where $O P W T P_{i 1}$ is WTP directly revealed by non-protest responses, and all coefficients and variables have the same definition as that in (3) and those in Table 1 (see Appendix). The mean WTP can, thus, be computed by taking the average of all estimated $O P W T P_{i j}$.
2.3.2. Format of pure discrete choice. The empirical counterpart of model (6) has to be specified for estimation. All explanatory variables have to be ready, especially the Heckman inverse Mills ratio modified from the bivariate probit model. The final estimation of WTP is to include protest, non-protest, and noanswer responses specified as follows:

$$
\begin{aligned}
& D W T P_{i j}=\alpha_{D}+\beta_{1 D} \text { Visit }_{i j}+\beta_{2 D} \text { Environ }_{i j}+\beta_{3 D} \text { Age }_{i j}+\beta_{4 D} \text { Eduyear }_{i j}+\beta_{5 D} \text { Occ1 }_{i j} \\
& +\beta_{6 D} O c c 2_{i j}+\beta_{7 D} O c c 3_{i j}+\beta_{8 D} O c c 4_{i j}+\beta_{9 D} \text { Income }_{i j}+\beta_{10 D} \text { Organiz }_{i j} \\
& +\beta_{11 D}^{\prime} \text { Volunteer }_{i j}+\beta_{12 D} \text { Donate }_{i j}+\beta_{13 D} \text { Distance }_{i j}+\omega_{D} \text { HIMR }_{i 1}+\varepsilon_{D i 1} \\
& i=1,2,3, \ldots, n \quad j=1,2,3
\end{aligned}
$$

where Heckman's inverse Mills ratio $\left(H I M R_{1}\right)$ is for non-protest responses and all coefficients and variables have the same definition as that in (6) and Table 1 (see Appendix). The mean WTP can, thus, be computed by taking the average of all estimated $D W T P_{i j}$.

\subsubsection{Format of hybrid type with discrete choice and} open WTP revelation. Similar to the pure discrete choice format, the type of response must, first, be classified via multinomial logit model before estimation is conducted. The final open WTP revelation is, then, estimated by modifying the bivariate probit model, where Heckman's inverse Mills ratio is generated. The final estimation of WTP with inclusion of all responses of protest, non-protest, and no-answer, i.e., the empirical specification of equation (7), is listed in the equation below (11)

$$
\begin{aligned}
\text { TWTP }_{i j}= & \alpha_{T}+\beta_{1 T} \text { Visit }_{i j}+\beta_{2 T} \text { Environ }_{i j}+\beta_{3 T} \text { Age }_{i j}+\beta_{4 T} \text { Eduyear }_{i j}+\beta_{5 T} \text { Occ }_{i j}+\beta_{6 T} \text { Occ }_{i j} \\
& +\beta_{7 T} \text { Occ }_{i j}+\beta_{8 T} \text { Occ }_{i j}+\beta_{9 T} \text { Income }_{i j}+\beta_{10 T} \text { Organiz }_{i j}+\beta_{11 T} \text { Volunteer }_{i j} \\
& +\beta_{12 T} \text { Donate }_{i j}+\beta_{13 T} \text { Distance }_{i j}+\omega_{T} \text { HIMR }_{i 1}+\varepsilon_{T i 1} \\
& i=1,2,3, \ldots, n, \quad j=1,2,3
\end{aligned}
$$

where all coefficients and variables have the same definition as that in (7) and Table 1 in Appendix. The mean WTP can, thus, be computed by taking the average of all estimated $T W T P_{i j}$.

\section{Results and discussions}

Before analyses proceed, an overview of the full sample and subgroup of the sample for all variables is undertaken. Table 1 (see Appendix) is the summary of all variables used in different stages of estimations in the general model constructed in this study. The described subgroups are non-protest, protest, and no-answer responses. We can observe from the descriptive results that most average values of independent variables are quite similar among groups, except for a few variables. This indicates that each subgroup, i.e., non-protest, protest, and no-answer responses, has similar characteristics, thus, removing or including any subgroup of responses for analysis purpose will have similar impacts for any combination of subgroups of responses.

The percentage of respondents with occupation of doctor or in any related service sector, volunteering in environmental nongovernmental organizations (NGO) groups, and donating to environmental NGO groups for the subgroup of protest responses have relative lower mean values as compared to those of the full sample. Additionally, the protest responses are from a group of respondents that reside close to the study site. That is, they are also concerned about protection of the site, since their evaluation of the environmental function of the Wetland is not significantly lower than that of the average sample. However, they pay much more attention to the limitations on their ability to develop or utilize land after the Wetland is realized. Similar to the subsample giving protest responses, fewer among the subgroup giving no-answer responses have donated to environmental NGO groups.

The results of the estimated probability by (8) that identifies the types of responses under different elicitation formats are presented in Table 2 .

Among the three subgroups, the subgroup of nonprotest responses is used as a reference group. The magnitudes of estimated results shown in Table 2 are the other two subgroups relative to the reference subgroup of non-protest responses. Once the probability of response is identified as part of each subgroup it belongs to, then, estimation of WTP for different elicitation formats will be done individually. 
Table 2. Results of multinomial logit estimation for identification of response type

\begin{tabular}{|l|l|c|c|c|}
\hline $\begin{array}{c}\text { Category of } \\
\text { response }\end{array}$ & Variable & Coefficient & $\begin{array}{c}\text { Standard } \\
\text { error }\end{array}$ & t-value \\
\hline \multirow{4}{*}{$\begin{array}{l}\text { Protest } \\
\text { response }\end{array}$} & Visit & 0.2830 & 0.1649 & $1.71^{*}$ \\
\cline { 2 - 5 } & Eduyear & -0.0835 & 0.0318 & $-2.63^{* \star}$ \\
\cline { 2 - 5 } & Income & -0.0081 & 0.0036 & $-2.25^{\star \star *}$ \\
\cline { 2 - 5 } & Organiz & -0.6467 & 0.5979 & -1.08 \\
\cline { 2 - 5 } & Volunteer & -0.4131 & 0.3493 & -1.18 \\
\cline { 2 - 5 } & Donate & -0.5997 & 0.3666 & $-1.64^{*}$ \\
\cline { 2 - 5 } & Constant & 0.2579 & 0.3885 & 0.66 \\
\hline \multirow{5}{*}{$\begin{array}{l}\text { No-answer } \\
\text { response }\end{array}$} & Visit & -0.3302 & 0.1671 & $-1.98^{\star *}$ \\
\cline { 2 - 5 } & Eduyear & -0.0208 & 0.0093 & $-2.24^{\star *}$ \\
\cline { 2 - 5 } & Income & -0.0061 & 0.0030 & $-2.03^{\star *}$ \\
\cline { 2 - 5 } & Organiz & 0.2291 & 0.5204 & 0.44 \\
\cline { 2 - 5 } & Volunteer & -0.1852 & 0.3760 & -0.49 \\
\cline { 2 - 5 } & Donate & -0.6649 & 0.4011 & $-1.66^{*}$ \\
\cline { 2 - 5 } & Constant & -0.5854 & 0.4948 & -1.18 \\
\hline
\end{tabular}

Note: the reference group is the group of non-protest responses.

Without involving complicated and detailed WTP estimation steps for each elicitation format, the final estimated outcomes are displayed in Table 3 in Appendix for equations (3), (6), and (7). The outcomes also show the estimation results of traditional Tobit model for format of direct revelation of WTP, hybrid type format with discrete choice and open WTP revelation, and bivariate probit model for pure discrete choice format. However, the general model has the advantage of accounting for protests and no-answer response simultaneously. With accounting for both neglected and inappropriately handled subgroups for any category of elicitation format, the estimation results turn out to be statistically significant. It is easy to observe from Table 3 (see Appendix) that numbers of significant variables from the general model for any format of elicitation type are much greater than those from traditional modification and estimation.

According to the estimation results from Table 3 (see Appendix), the corresponding annual mean WTP per household for each elicitation format can, thus, be computed. Moreover, the total WTP can also be calculated by multiplying total number of households. All the results are presented in Table 4 (see Appendix). It clearly shows that the average WTPs per household each year are the lowest under traditional treatment for all types of elicitation formats when protestresponses are included, i.e., the results in column (C). Since such treatment normally censors the protest responses at zero, the average WTP will, then, be underestimated. In contrast, exclusion of protest responses shown as the results in column (D), has the highest average WTP per household annually.

The average WTPs per household each year are systematically higher in the traditional treatment with inclusion of non-protest responses only, and much lower for the responses with inclusion of protest responses censored at zero than the results estimated from the general model results. Although the average WTP might not be consistently higher or lower compared to results estimated from the general model, the total benefits are systematically biased downwards from traditional treatment. This set of data has $23.83 \%$ protest responses and $16.95 \%$ no-answer responses. There are $40.78 \%$ protest and no-answer responses in total. While calculating the total benefits, the total percentage of households has to reduce the same percentage as the protest and no-answer responses appear in the data. That is, there is only $59 \%$ of the total number of households accounted for when the total WTP is computed. This consistently shows that the protest responses treated by the traditional way, i.e., to exclude them or to include them in an inappropriate way, will result in underestimated total WTP.

Furthermore, the results also show that the total WTP estimated by traditional treatment for inclusion of protest responses and censored reveals that WTP or predicted WTP at zero under any format of elicitation type systematically show much more severe underestimation than those when protest responses are excluded. The degree of underestimation is ranged from a low of $26 \%$ to a high of $40 \%$. Since traditional modification of protest responses tends to exclude them from estimation, the higher percentage of protest responses occurs the greater degree of underestimation of total estimated WTP will, then, result. The degree of underestimation is ranged from a low of $52 \%$ to a high of $67 \%$.

The overall total WTP from the general model with inclusion of protest and no-answer responses under different types of elicitation formats is higher than those estimated by traditional treatment. The differences might arise from the average WTP estimation or the reduction of total number of households due to the exclusion of protest or noanswer responses. The results show that the general model can estimate protest responses in a relatively simple way. Most importantly, the general model can take into account no-answer responses in the estimation simultaneously. This is a big step toward resolving issues of protest and no-answer responses in the current literature.

\section{Conclusion}

The general model developed in this study is employed to deal with the protest responses and noanswer responses. This model is general in three ways: simultaneously accounting for protest and noanswer responses, its applicability to all kinds of elicitation formats in all kinds of contingent valuation applications, and its simplicity in 
estimation. Although there are various approaches to deal with protest responses, they are either too complicated or only suitable for specific elicitation methods. Most importantly, previous estimation methods only treat protest responses, but don't deal with no-answer responses. The general model constructed here can be used to include protest and no-answer responses at the same time. This general model mainly adopts a Heckman's inverse Mills ratio from a multinomial logit model once a group of respondents is identified as providing protest responses or no-answer responses.

To demonstrate this model, it is applied to a set of data gathered with a double-bounded choice with open-ended follow-up contingent valuation method. As such, all types of elicitation formats classified in this study will have data for demonstration. Creation of inverse Mills ratio and continuously carrying these ratios in the subsequent estimation is the distinctive step for the modification of different types of elicitation formats in our general model. The results generally indicate that these ratios are significantly different from zero. This means that accounting for these Mills ratios does have an important role in such modification when protest responses and/or no-answer responses are both taken into account. In addition to dealing with these responses, this model can be applied to samples in which the information is relatively incomplete. That is, such a model can accomplish benefit transfer between a sample with complete information and one with incomplete information.

Empirical estimations for all types of models accomplished here demonstrate the feasibility of the general model proposed in this study in dealing with protests and/or no-answer responses. Such general model can be easily used to bring into the potential excluded responses, which could cause underestimation or overestimation of mean willingness to pay or mean willingness to accept conducted by contingent valuation method. This general model is not only important, but also essential from the methodological perspective in implementing the popular evaluation method such as contingent valuation method. As the benefit, cost, or damage is a necessary component in the implementation of benefit cost analysis, evaluation with less imperfection is required. The general model proposed in this study can appropriately play such a role.

\section{Acknowledgement}

The financial support of this study from Ministry of Science and Technology of Taiwan (National Science Council) through project NSC 102-2410-H$002-161$ is sincerely appreciated.

\section{References}

1. Alberini, A., Boyle, K., and Welsh, M. (2003). Analysis of contingent valuation data with multiple bids and response options allowing respondents to express uncertainty. Journal of Environmental Economics and Management, 45(1), 40-62.

2. Alvarez-Farizo, B. (1999). Estimating the benefits of agri-environmental policy: Econometric issues in open-ended contingent valuation studies. Journal of Environmental Planning and Management, 42(1), 23-43.

3. Arrow, K., Solow, R., Portney, P. R., Leamer, E. E., Radner, R., and Schuman, H. (1993). Report of the NOAA Panel on contingent valuation. Federal Register, 58(10), 4600-4614.

4. Atkinson, G., Morse-Jones, S., Mourato, S., and Provins, A. (2012). When to take 'no' for an answer? Environmental and Resource Economics, 51(4), 497-523.

5. Balcombe, K., and Fraster, I. (2009). Dichotomous-choice contingent valuation with 'don't know' responses and misreporting. Journal of Applied Econometrics, 24(7), 1137-1152.

6. Barrio, M., and Loureiro, M. M. L. (2010). An alternative approach to identifying protest attitudes in choice experiments. Bioecon Conference, 58(3), 27-28.

7. Bateman, I. J., Langford, I. H., Turner, R. K., Willis, K. G., and Garrod, G. D. (1995). Elicitation and truncation effects in contingent valuation studies. Ecological Economics, 12(2), 161-179.

8. Bishop, R. C., and Heberlein, T. A. (1979). Measuring values of extramarket goods: Are indirect measures biased? American Journal of Agricultural Economics, 61(5), 926-930.

9. Bourguignon, F., Fournier, M., and Gurgand, M. (2007). Selection bias corrections based on the multinomial logit model: Monte Carlo comparisons. Journal of Economics Surveys, 21(1), 174-205.

10. Brouwer, R., and Martín-Ortega, J. (2012). Modeling self-censoring of polluter pays protest votes in stated preference research to support resource damage estimations in environmental liability. Resource and Energy Economics, 34(1), 151-166.

11. Carson, R. T., and Sun, Y. (2007). The Tobit model with a non-zero threshold. Econometrics Journal, 10(3), 488-502.

12. Cragg, J. G. (1971). Some statistical models for limited dependent variables with application to the demand for durable goods. Econometrica, 39(5), 829-844.

13. Cunha-e-Sá, M., Madureira, L., Nunes, L. C., and Otrachshenko, V. (2012). Protesting and justifying: A latent class model for contingent valuation with attitudinal data. Environmental and Resource Economics, 52(4), 531-548. 
14. Dalmau-Matarrodona, E. (2001). Alternative approaches to obtain optimal bid values in contingent valuation studies and to model protest zeros: Estimating the determinants of individual's willingness to pay for home care service in day case surgery. Health Economics, 10(2), 101-118.

15. Dubin, J. A., and McFadden, D. L. (1984). An econometric analysis of residential electric appliance holdings and consumption. Econometrica, 52(2), 345-362.

16. Dziegielewska, D. A., and Mendelsohn, R. (2007). Does 'no' mean 'no'? a protestmethodology. Environmental and Resource Economics, 38(1), 71-87.

17. Fonta, W. M., Ichoku, H. E., and Kabubo-Mariara, J. (2010). The effect of protest zeros on estimates of willingness to pay in healthcare contingent valuation analysis. Applied Health Economics and Health Policy, 8(4), 225-237.

18. Groothuis, P. A., and Whitehead, J. C. (2002). Does don't know mean no? analysis of 'don't know' responses in dichotomous choice contingent valuation questions. Applied Economics, 34(15), 1935-1940.

19. Halstead, J. M., Luloff, A. E., and Stevens, T. H. (1992). Protest bidders in contingent valuation. Northeastern Journal of Agriculture Resource Economics, 21(2), 160-169.

20. Havet, N., Morelle, M., Remonnay, R., and Carrere, M. (2012). Econometric treatment of few protest response in willingness-to-pay studies: An application in health care. Recherches Économiques de Louvain, 78(2), 53-74.

21. Heckman, J. J. (1979). Sample selection bias as a specification error. Econometrica, 47(1), 153-161.

22. Hung, C.-M., Shaw, D., Lin, H.-I., Wu, P.-I., Chien, Y.-L., Liou, J.-L., Huang, T.-H. (2012). Application and Review of Environmental Impact and Benefit-Cost Analysis of Project Development. EPA-101-E103-02-207. Project Supported by Environmental Protection Agency. Chung-Hua Institution for Economic Research, Taipei, Taiwan.

23. Hsiao, C., and Sun, B. H. (1998). Modeling survey response bias: with an analysis of the demand for an advanced electronic device. Journal of Econometrics, 89(1-2), 13-39.

24. Hones, N., Sophoulis, C. M., and Malesios, C. (2008). Economic valuation of coastal water quality and protest responses: A case study in Mitilini, Greece. The Journal of Socio-Economics, 37(6), 2478-2491.

25. Jorgensen, B. S., Syme, G. J., Bishop, B. J., and Nancarrow, B. E. (1999). Protest response in contingent valuation. Environmental and Resource Economics, 14(1), 131-150.

26. Langford, I. H., Bateman, I. J., and Langford, H. D. (1996). A multilevel modeling approach to triple-bounded dichotomous choice contingent valuation. Environmental and Resource Economics, 7(2), 192-211.

27. Li, C. Z., and Mattson, L. (1995). Discrete choice under preference uncertainty: An improved structural model for contingent valuation. Journal of Environment Economics and Management, 28(2), 256-269.

28. Lindsey, G. (1994). Market models, protest bids, and outliers in contingent valuation. Journal of Water Resources Planning and Management, 120(1), 121-129.

29. Meyerhoff, J., and Liebe, U. (2006). Protest beliefs in contingent valuation: Explaining their motivation. Ecological Economics, 57(4), 583-594.

30. Meyerhoff, J., and Liebe, U. (2009). Status quo effect in choice experiments: Empirical evidence on attitudes and choice task complexity. Land Economics, 85(3), 515-528.

31. Meyerhoff, J., Bartczak, A., and Liebe, U. (2012). Protester or non-protester: A binary state? On the use (and non-use) of latent class models to analyses protesting in economic valuation. The Australian Journal of Agricultural and Resource Economics, 56(3), 438-454.

32. Presser, S., and Schuman, H. (1980). The measurement of a middle position in attitude surveys. Public Opinion Quarterly, 44(1), 70-85.

33. Randall, A., Ives, B., and Eastman, C. (1974). Bidding games for valuation of aesthetic environment improvements. Journal of Environmental Economics and Management, 1(2), 132-149.

34. Ready, R. C., Navrud, S., and Dubourg, W. R. (2001). How do respondents with uncertain willingness to pay answer contingent valuation questions? Land Economics, 77(3), 315-326.

35. Reiser, B., and Shechter, M. (1999). Incorporating zero values in the economic valuation of environmental program benefits. Environmetrics, 10(1), 87-101.

36. Scarpa, R., and Bateman, I. (2000). Efficiency gains afforded by improved bid design versus follow-up valuation questions in discrete-choice CV studies. Land Economics, 76(2), 299-311.

37. Shaikh, S. L., Sun, L., and van Kooten, G. C. (2007). Treating respondent uncertainty in contingent valuation: A comparison of empirical treatments. Ecological Economics, 62(1), 115-125.

38. Strazzera, E., Genius, M., Scarpa, R., and Hutchinson, G. (2003). The effect of protest votes on the estimates of WTP for use values of recreational sites. Environmental and Resource Economics, 25(4), 461-476.

39. Wang, H. (1997). Treatment of 'don't know' response in contingent valuation surveys: A random valuation model. Journal of Environment Economics and Management, 32(2), 219-232.

40. Whitehead, J. C., Groothuis, P. A., and Blomquist, G. C. (1993). Testing for non-response and sample selection bias in contingent valuation: Analysis of a combination of phone/mail survey. Economic Letters, 41(2), 215-220.

41. Wu, P.-I, Cheng,W.-F., and Su, M.-T. (2004). Model of multiple-hurdle with decision process: A possible resolution of protest responses in contingent valuation questions. Agriculture and Economics, 33, 29-60.

42. Zoltán, S. (2011). Reducing protest responses by deliberative monetary valuation: Improving the validity of biodiversity valuation. Ecological Economics, 72(15), 37-44. 


\section{Appendix}

Table 1. Definition and mean values for all variables used in different estimations ${ }^{1}$

\begin{tabular}{|c|c|c|c|c|c|}
\hline $\begin{array}{l}\text { Variable } \\
\text { and } \\
\text { notation }\end{array}$ & $\begin{array}{l}\text { Definition of variable } \\
\quad \text { (unit) }\end{array}$ & Full sample & Non-protest sample & $\begin{array}{l}\text { Protest } \\
\text { responses }\end{array}$ & $\begin{array}{l}\text { No-answer } \\
\text { responses }\end{array}$ \\
\hline \multicolumn{6}{|c|}{ Dependent variables } \\
\hline WTP & $\begin{array}{l}\text { The final maximum WTP in discrete choice followed by } \\
\text { open-ended elicitation CVM of the question } \\
\text { (NT\$/household/year) }\end{array}$ & -- & $\begin{array}{c}992.43 \\
(958.16)\end{array}$ & $\begin{array}{l}0 \\
(0)\end{array}$ & -- \\
\hline Cate & $\begin{array}{l}\text { Classification of respondent's type, } 1 \text { indicates non- } \\
\text { protest, } 2 \text { indicates protest, and } 3 \text { indicates no-answer } \\
\text { responses }\end{array}$ & & & & \\
\hline \multicolumn{6}{|c|}{ Independent variables } \\
\hline Visit & $\begin{array}{l}\text { Dummy variable, whether has visited the Wetland, } 1 \\
\text { means "yes" and } 0 \text { means "no" }\end{array}$ & $\begin{array}{l}0.21 \\
(0.41)\end{array}$ & $\begin{array}{c}0.20 \\
(0.40)\end{array}$ & $\begin{array}{l}0.27 \\
(0.44)\end{array}$ & $\begin{array}{l}0.16 \\
(0.37)\end{array}$ \\
\hline Environ & $\begin{array}{l}\text { Respondent's evaluation of the importance of wetlands } \\
\text { in regard to environmental functions (scale from 1-10) }\end{array}$ & $\begin{array}{c}8.78 \\
(1.64)\end{array}$ & $\begin{array}{c}8.98 \\
(1.45)\end{array}$ & $\begin{array}{c}8.30 \\
(1.93)\end{array}$ & $\begin{array}{c}8.72 \\
(1.68)\end{array}$ \\
\hline Age & Age of the respondent (years) & $\begin{array}{c}55.35 \\
(13.53) \\
\end{array}$ & $\begin{array}{c}55.74 \\
(13.72) \\
\end{array}$ & $\begin{array}{c}52.82 \\
(13.44)\end{array}$ & $\begin{array}{c}57.57 \\
(12.46)\end{array}$ \\
\hline Eduyear & Respondent's education (years) & $\begin{array}{c}11.85 \\
(3.86) \\
\end{array}$ & $\begin{array}{c}12.26 \\
(3.68) \\
\end{array}$ & $\begin{array}{c}10.92 \\
(4.16) \\
\end{array}$ & $\begin{array}{c}11.75 \\
(3.81) \\
\end{array}$ \\
\hline Occ1 & $\begin{array}{l}\text { Dummy Variable } 1 \text { if respondent is civil servant, teacher, } \\
\text { or soldier; } 0 \text { otherwise }\end{array}$ & $\begin{array}{l}0.07 \\
(0.26)\end{array}$ & $\begin{array}{c}0.08 \\
(0.28)\end{array}$ & $\begin{array}{l}0.09 \\
(0.17)\end{array}$ & $\begin{array}{c}0.09 \\
(0.28)\end{array}$ \\
\hline Occ2 & $\begin{array}{l}\text { Dummy variable } 1 \text { if respondent is a merchandiser, } \\
\text { manufacturer, or high-technological worker; } 0 \text { otherwise }\end{array}$ & $\begin{array}{c}0.29 \\
(0.45)\end{array}$ & $\begin{array}{c}0.30 \\
(0.46)\end{array}$ & $\begin{array}{c}0.30 \\
(0.46)\end{array}$ & $\begin{array}{c}0.22 \\
(0.41)\end{array}$ \\
\hline Occ3 & $\begin{array}{l}\text { Dummy variable } 1 \text { if respondent is farmer or fisherman; } 0 \\
\text { otherwise }\end{array}$ & $\begin{array}{c}0.04 \\
(0.20)\end{array}$ & $\begin{array}{c}0.04 \\
(0.19)\end{array}$ & $\begin{array}{c}0.04 \\
(0.20)\end{array}$ & $\begin{array}{l}0.06 \\
(0.23)\end{array}$ \\
\hline Occ4 & $\begin{array}{l}\text { Dummy variable } 1 \text { if respondent is a doctor or in service } \\
\text { or financial sector; } 0 \text { otherwise }\end{array}$ & $\begin{array}{c}0.35 \\
(0.48)\end{array}$ & $\begin{array}{c}0.35 \\
(0.48)\end{array}$ & $\begin{array}{c}0.29 \\
(0.45)\end{array}$ & $\begin{array}{c}0.42 \\
(0.49)\end{array}$ \\
\hline Income & $\begin{array}{l}\text { Total household income of respondent in } 2012(10,000 \\
\text { NT\$) }\end{array}$ & $\begin{array}{c}38.17 \\
(37.75)\end{array}$ & $\begin{array}{c}40.92 \\
(39.14)\end{array}$ & $\begin{array}{c}35.21 \\
(38.00)\end{array}$ & $\begin{array}{c}32.83 \\
(31.04)\end{array}$ \\
\hline Organiz & $\begin{array}{l}\text { Dummy variable } 1 \text { if respondent has been an } \\
\text { environmental NGO member; } 0 \text { otherwise }\end{array}$ & $\begin{array}{c}0.08 \\
(0.27)\end{array}$ & $\begin{array}{c}0.09 \\
(0.28)\end{array}$ & $\begin{array}{c}0.04 \\
(0.20)\end{array}$ & $\begin{array}{c}0.09 \\
(0.28)\end{array}$ \\
\hline Volunteer & $\begin{array}{l}\text { Dummy variable } 1 \text { if respondent has served as an } \\
\text { environmental NGO volunteer; } 0 \text { otherwise }\end{array}$ & $\begin{array}{c}0.20 \\
(0.40)\end{array}$ & $\begin{array}{c}0.22 \\
(0.42)\end{array}$ & $\begin{array}{c}0.14 \\
(0.35)\end{array}$ & $\begin{array}{c}0.19 \\
(0.39)\end{array}$ \\
\hline Donate & $\begin{array}{l}\text { Dummy variable } 1 \text { if respondent has donated to any } \\
\text { environmental NGO group; } 0 \text { otherwise }\end{array}$ & $\begin{array}{c}0.18 \\
(0.38)\end{array}$ & $\begin{array}{c}0.22 \\
(0.42)\end{array}$ & $\begin{array}{c}0.11 \\
(0.32)\end{array}$ & $\begin{array}{c}0.13 \\
(0.34)\end{array}$ \\
\hline Distance & $\begin{array}{l}\text { Rectilinear or driving distance fromr espondent's home to } \\
\text { the Wetland for non-visitor and visitor, respectively } \\
\text { (kilometers) }\end{array}$ & $\begin{array}{c}111.17 \\
(57.13)\end{array}$ & $\begin{array}{c}118.64 \\
(59.19)\end{array}$ & $\begin{array}{c}98.03 \\
(52.40)\end{array}$ & $\begin{array}{l}103.77 \\
(51.7)\end{array}$ \\
\hline Sample size & & 405 & 239 & 97 & 69 \\
\hline
\end{tabular}

Note: numbers in parentheses are standard deviation of each variable. 
Table 3. Comparison of estimation results of general model with inclusion of non-protest, protest, and no-answer responses and traditional Tobit with protest responses

\begin{tabular}{|c|c|c|c|c|c|c|c|c|c|c|c|c|}
\hline \multirow{3}{*}{ Variable } & \multicolumn{4}{|c|}{ Direct Revelation of WTP Format } & \multicolumn{4}{|c|}{ Pure Discrete Choice Format } & \multicolumn{4}{|c|}{ Hybrid Format with Discrete Choice and Open WTP Revelation } \\
\hline & \multicolumn{2}{|c|}{$\begin{array}{l}\text { Inclusion of protest and no- } \\
\text { answer responses under } \\
\text { general model }\end{array}$} & \multicolumn{2}{|c|}{$\begin{array}{l}\text { Inclusion of protest } \\
\text { responses under traditional } \\
\text { Tobit model }\end{array}$} & \multicolumn{2}{|c|}{$\begin{array}{l}\text { Inclusion of protest and no- } \\
\text { answer responses under } \\
\text { general model }\end{array}$} & \multicolumn{2}{|c|}{$\begin{array}{c}\text { Inclusion of protest } \\
\text { responses under } \\
\text { traditional bivariate Probit } \\
\text { model }\end{array}$} & \multicolumn{2}{|c|}{$\begin{array}{l}\text { Inclusion of protest and no- } \\
\text { answer responses under } \\
\text { general model }\end{array}$} & \multicolumn{2}{|c|}{$\begin{array}{l}\text { Inclusion of protest } \\
\text { responses under } \\
\text { traditional Tobit model2 }\end{array}$} \\
\hline & Coefficient & t-value & Coefficient & $\mathrm{t}$-value & Coefficient & $\mathrm{t}$-value & Coefficient & t-value & Coefficient & $\mathrm{t}$-value & Coefficient & t-value \\
\hline Visit & 1086.08 & $2.38^{* \star *}$ & -270.54 & $-1.78^{\star}$ & 31.33 & $1.67^{\star}$ & -0.08 & -0.51 & -106.82 & -1.42 & -270.54 & $-1.78^{\star}$ \\
\hline Environ & 101.06 & $\underset{*}{5.94^{* *}}$ & 180.16 & $4.12^{* \star *}$ & 18.14 & $4.70^{\star \star *}$ & 0.19 & $4.91^{\star * \star}$ & 126.56 & $7.43^{\star * *}$ & 180.16 & $4.12^{* \star *}$ \\
\hline Age & -3.79 & -1.23 & 2.87 & 0.52 & 0.74 & 1.28 & 0.01 & 0.84 & -2.50 & -0.82 & 2.87 & 0.52 \\
\hline Eduyear & -65.12 & -1.11 & 22.33 & 1.17 & 19.38 & $9.27^{\star \star \star}$ & 0.03 & $1.80^{*}$ & 10.27 & 1.06 & 22.33 & 1.17 \\
\hline Occ1 & 586.54 & $\underset{*}{2.83^{* \star}}$ & 623.53 & $2.06^{\star \star}$ & -188.58 & $-5.27^{\star \star \star}$ & 0.28 & 1.08 & 413.45 & $2.14^{\star *}$ & 623.53 & $2.06^{\star \star}$ \\
\hline Occ2 & 53.06 & 0.59 & 66.13 & 0.38 & -189.17 & $-7.61^{\star \star \star}$ & 0.01 & 0.04 & -206.13 & $-2.63^{\star \star \star}$ & 66.13 & 0.38 \\
\hline Occ3 & 144.93 & 0.83 & 317.30 & 0.85 & -49.76 & -1.51 & 0.06 & 0.19 & -242.16 & -1.32 & 317.30 & 0.85 \\
\hline Occ4 & 169.11 & $1.82^{\star}$ & 237.65 & 1.27 & -130.82 & $-6.88^{\star \star \star}$ & 0.05 & 0.34 & -31.37 & -0.37 & 237.65 & 1.27 \\
\hline Income & 16.50 & $\underset{*}{3.09^{* *}}$ & 2.99 & 1.50 & 4.81 & $9.07^{\star \star \star}$ & 0.01 & 1.35 & 4.35 & $3.36^{\star \star \star}$ & 3.00 & 1.50 \\
\hline Organiz & -1563.33 & $3.30^{\star * *}$ & 215.54 & 0.65 & -237.44 & $-5.04^{\star \star *}$ & 0.16 & 0.70 & -237.44 & 0.08 & 215.54 & 0.65 \\
\hline Volunteer & -43.47 & -0.14 & 235.49 & 1.34 & 358.95 & $15.64^{\star \star \star}$ & 0.29 & $1.87^{*}$ & 358.95 & 1.15 & 235.49 & 1.34 \\
\hline Donate & 1038.51 & 1.95 & 352.90 & $1.93^{\star \star}$ & 237.47 & $10.79^{\star \star \star}$ & 0.25 & 1.59 & 237.47 & $2.99^{\star \star \star}$ & 352.90 & $1.93^{\star \star}$ \\
\hline Distance & -1.95 & $3.09^{* * *}$ & 0.04 & 0.03 & -0.01 & -0.01 & 0.01 & 0.52 & -0.01 & $-3.83^{\star \star *}$ & 0.04 & 0.03 \\
\hline MLIMRA & 8053.28 & $2.96^{* \star}$ & -- & -- & -- & -- & -- & -- & -- & -- & -- & -- \\
\hline MLIMRF & -10940.38 & $3.01^{-}$ & -- & -- & -- & -- & -- & -- & -- & -- & -- & -- \\
\hline HIMR & -- & -- & -- & -- & -128.25 & $-6.54^{\star \star \star}$ & -- & -- & -128.25 & $9.13^{\star \star \star}$ & -- & -- \\
\hline constant & $\begin{array}{l}-1713.71 \\
\end{array}$ & $-0.72^{\star \star \star}$ & -1890.60 & $-3.66^{* \star *}$ & 893.81 & $18.69^{\star \star \star}$ & -2.23 & $-4.90^{\star \star \star}$ & 893.81 & $-3.54^{\star \star \star}$ & -1890.60 & $-3.66^{* \star \star}$ \\
\hline $\begin{array}{l}\text { Sample } \\
\text { size }\end{array}$ & \multicolumn{2}{|c|}{405} & \multicolumn{2}{|c|}{336} & \multicolumn{2}{|c|}{405} & \multicolumn{2}{|c|}{336} & \multicolumn{2}{|c|}{405} & \multicolumn{2}{|c|}{336} \\
\hline $\begin{array}{l}\text { Mean } \\
\text { WTP (s.e.) }\end{array}$ & \multicolumn{2}{|c|}{$\begin{array}{c}957 \\
(14.83)\end{array}$} & \multicolumn{2}{|c|}{$\begin{array}{c}461 \\
(16.43)\end{array}$} & \multicolumn{2}{|c|}{$\begin{array}{c}1,404 \\
(14.04)\end{array}$} & \multicolumn{2}{|c|}{$\begin{array}{c}554 \\
(41.53)\end{array}$} & \multicolumn{2}{|c|}{$\begin{array}{c}966 \\
(22.19)\end{array}$} & \multicolumn{2}{|c|}{$\begin{array}{c}461 \\
(25.45)\end{array}$} \\
\hline
\end{tabular}

Note 1: Numbers with one, two, and three asterisks “*”, “**”, and “***” indicate coefficients that are significant at $10 \%, 5 \%$, and $1 \%$ significance levels, respectively.

Note 2: Estimation results for format of "hybrid format with discrete choice and open WTP revelation and that of "direct revelation of WTP" are the same, since the final open revelation of WTP is taken for analysis, while protest responses are included in the Tobit model. 
Table 4. Comparison of total WTP from traditional treatment of protest and no-answer responses and from general model under different types of elicitation categories

\begin{tabular}{|c|c|c|c|c|c|c|c|c|c|c|c|c|}
\hline \multirow{2}{*}{$\begin{array}{l}\text { Type of } \\
\text { elicitation } \\
\text { format }\end{array}$} & \multicolumn{3}{|c|}{$\begin{array}{l}\text { Inclusion of protest and no-answer responses } \\
\text { under general model (A) }\end{array}$} & \multicolumn{3}{|c|}{$\begin{array}{l}\text { Inclusion of protest responses under general } \\
\text { model (B) }\end{array}$} & \multicolumn{3}{|c|}{$\begin{array}{l}\text { Inclusion of protest responses under traditional } \\
\text { treatment (C) }{ }^{1}\end{array}$} & \multicolumn{3}{|c|}{$\begin{array}{l}\text { Traditional treatment for non-protest responses } \\
\qquad(\mathrm{D})^{1}\end{array}$} \\
\hline & $\begin{array}{c}\text { WTP } \\
\text { (NT\$/yr } \\
\text { /household) }\end{array}$ & $\begin{array}{l}\text { Number of } \\
\text { households² } \\
\text { (thousand) }\end{array}$ & $\begin{array}{c}\text { Total } \\
\text { WTP } \\
\text { (million } \\
\text { NT\$) }\end{array}$ & $\begin{array}{c}\text { WTP } \\
\text { (NT\$/yr } \\
\text { /household) }\end{array}$ & $\begin{array}{l}\text { Number of } \\
\text { households² } \\
\text { (thousand) }\end{array}$ & $\begin{array}{c}\text { Total } \\
\text { WTP } \\
\text { (million } \\
\text { NT\$) } \\
\end{array}$ & $\begin{array}{c}\text { WTP } \\
\text { (NT\$/yr } \\
\text { /household) }\end{array}$ & $\begin{array}{l}\text { Number of } \\
\text { households² } \\
\text { (thousand) }\end{array}$ & $\begin{array}{c}\text { Total WTP3 } \\
\text { (million\$) }\end{array}$ & $\begin{array}{c}\text { WTP } \\
\text { (NT\$/yr } \\
\text { /household) }\end{array}$ & $\begin{array}{l}\text { Number of } \\
\text { households² } \\
\text { (thousand) }\end{array}$ & $\begin{array}{c}\text { Total } \\
\text { WTP3 } \\
\text { (million } \\
\text { NT\$) } \\
\end{array}$ \\
\hline $\begin{array}{l}\text { Direct } \\
\text { revelation } \\
\text { of WTP } \\
\text { format }\end{array}$ & 957 & $\begin{array}{l}8,192 \\
(100 \%)\end{array}$ & 7,840 & 955 & $\begin{array}{l}6,799 \\
(83 \%)\end{array}$ & 6,493 & 461 & $\begin{array}{l}6,799 \\
(83 \%)\end{array}$ & $\begin{array}{c}3,134 \\
(-60 \%) \\
(-52 \%)^{\prime \prime}\end{array}$ & 988 & $\begin{array}{l}4,833 \\
(59 \%)\end{array}$ & $\begin{array}{c}4,775 \\
(-39 \%) \\
(-26 \%) "\end{array}$ \\
\hline $\begin{array}{l}\text { Pure } \\
\text { discrete } \\
\text { choice } \\
\text { format }\end{array}$ & 1,401 & $\begin{array}{c}8,192 \\
(100 \%)\end{array}$ & 11,477 & 1,415 & $\begin{array}{l}6,799 \\
(83 \%)\end{array}$ & 9,621 & 554 & $\begin{array}{l}6,799 \\
(83 \%)\end{array}$ & $\begin{array}{c}3,767 \\
(-67 \%) \\
(-61 \%) "\end{array}$ & 1,433 & $\begin{array}{l}4,833 \\
(59 \%)\end{array}$ & $\begin{array}{c}6,926 \\
(-40 \%) ' \\
(-28 \%) "\end{array}$ \\
\hline & & & & & & & & & & & & \\
\hline $\begin{array}{l}\text { Hybrid } \\
\text { format } \\
\text { with } \\
\text { discrete } \\
\text { choice } \\
\text { and open } \\
\text { WTP } \\
\text { revelation }\end{array}$ & 966 & $\begin{array}{c}8,192 \\
(100 \%)\end{array}$ & 7,913 & 959 & $\begin{array}{l}6,799 \\
(83 \%)\end{array}$ & 6,520 & 461 & 6,799 & $\begin{array}{c}3,134 \\
(-60 \%)^{\prime} \\
(-52 \%)^{\prime \prime}\end{array}$ & 988 & $\begin{array}{l}4,833 \\
(59 \%)\end{array}$ & $\begin{array}{l}4,775 \\
(-40 \%)^{\prime} \\
(-27 \%)^{\prime \prime}\end{array}$ \\
\hline
\end{tabular}

Note 1: Traditional treatment while including protest responses are the results estimated from Tobit or bivariate Probit model as indicated in Table 3.

Note 2: The parentheses represent percent of total population when that protest responses or no-answer responses are included.

Note 3: The parentheses ( )'and ( )" represent the overestimated or underestimated of total WTP under traditional treatment and general model developed in this study. Where () ' $=(($ results from column (C) or (D)- results from column (A))/results from column (A); on the other hand, ( )"=((results from column (C) or (D)-results from column (B))/results from column (B). The negative percentage indicates that the percentage of total WTP estimated from the related traditional method is underestimated as compared to the general model developed in this study. In contrast, the positive percentage indicates that the percentage of total WTP from the related traditional method is overestimated. 